\begin{tabular}{|c|l|}
\hline Title & $\begin{array}{l}\text { Impact of control schemes of a monoval ent inverter-driven water-to-water heat pump with a desuperheater in } \\
\text { continental and subtropical climates through simulation }\end{array}$ \\
\hline Author(s) & Blanco, David L.; Nagano, Katsunori; Morimoto, Masahiro \\
\hline Citation & $\begin{array}{l}\text { A pplied Energy, 109, 374.386 } \\
\text { https://doi.org/10.1016/.apenergy.2012.12.047 }\end{array}$ \\
\hline Issue Date & 2013 09 \\
\hline Doc URL & http://hdl.handle.net/2115/54017 \\
\hline Type & article (author version) \\
\hline File Information & A ppEne.pdf \\
\hline
\end{tabular}

Instructions for use 


\title{
Impact of control schemes of a monovalent inverter-driven water-to- water heat pump with a desuperheater in continental and subtropical climates through simulation
}

\author{
David L. Blanco ${ }^{1}$, Katsunori Nagano, Masahiro Morimoto \\ Division of Human Environmental Systems, Graduate School of Engineering. Hokkaido \\ University, N13-W8. Kita Ku, Sapporo 060-8628, Japan
}

\begin{abstract}
An application of a novel steady-state simulation of a monovalent inverter-driven water-towater heat pump with a desuperheater is presented. The simulation is capable of modeling and managing the different operation modes of the system such as combined space heating and domestic hot water, in order to provide realistic results, from which four control schemes based on two electricity tariff plans were developed. The schemes were tested on a subject low energy house for Tokyo and Sapporo, in Japan, for the coldest day of the year and for the heating season. Emphasis was given to the short-term domestic hot water storage. The results show that the application of the schemes with a flexible electricity tariff had lower cost over the scheme that used the flat rate pricing plan. Moreover, it was shown that no unique scheme was able to minimize the cost and electrical consumption for both locations. Additionally, a tradeoff between lowest cost and lowest energy consumption was identified for Sapporo. The results of this research could be applied to develop a more robust control on monovalent heat pump systems.
\end{abstract}

Keywords: Ground source heat pump; Heating; Hot water; Coefficient of performance

\footnotetext{
${ }^{1}$ Corresponding Author Email: david.blanco.ch@eng.hokudai.ac.jp, david.blanco.ch@gmail.com Tel /Fax: +81-(0)11-706-6285
} 


\begin{tabular}{|c|c|}
\hline variable name & description and units \\
\hline \multicolumn{2}{|c|}{ Roman characters } \\
\hline$B$ & circulation pump \\
\hline$D H W$ & domestic hot water \\
\hline COP & coefficient of performance \\
\hline$C_{p}$ & specific heat at constant pressure $\left[\mathrm{kJ} \mathrm{kg}^{-1} \mathrm{~K}^{-1}\right]$ \\
\hline freq & frequency $[\mathrm{Hz}]$ \\
\hline$G$ & volumetric flow rate $\left[\mathrm{m}^{3} \mathrm{hr}^{-1}\right]$ \\
\hline GSHP & Ground source heat pump \\
\hline$H$ & specific enthalpy $\left[\mathrm{kJkg}^{-1}\right]$ \\
\hline$H V A C$ & Heating ventilation and air conditioning \\
\hline$H X$ & Heat exchanger \\
\hline$\dot{m}$ & refrigerant mass flow rate $\left[\mathrm{kgs}^{-1}\right]$ \\
\hline monovalent & $\begin{array}{l}\text { classification of systems capable of providing by themselves the thermal } \\
\text { requirements of a home throughout a yearly cycle without the need of } \\
\text { complementary systems }\end{array}$ \\
\hline $\bmod$ & operation mode of the system \\
\hline$P$ & pressure $[\mathrm{MPa}]$ \\
\hline$Q$ & heat transfer $[\mathrm{kW}]$ \\
\hline$\tilde{S C}$ & Space cooling \\
\hline SH & space heating \\
\hline step & expansion valve step N.D. \\
\hline$T$ & temperature $\left[{ }^{\circ} \mathrm{C}\right]$ \\
\hline$t$ & time \\
\hline UTES & Underground thermal energy storage \\
\hline$V$ & volume $\left[\mathrm{m}^{3}\right]$ \\
\hline$W_{e l}$ & electrical compressor input $[\mathrm{kW}]$ \\
\hline $24 \mathrm{hr}$ & 24 hours \\
\hline \multicolumn{2}{|l|}{ Greek characters } \\
\hline$\eta$ & efficiency N.D. \\
\hline$\rho$ & density $\left[\mathrm{kgm}^{-3}\right]$ \\
\hline \multicolumn{2}{|l|}{ Subscripts } \\
\hline$c$ & condenser \\
\hline$d$ & desuperheater \\
\hline$D H W$ & domestic hot water \\
\hline$e$ & evaporator \\
\hline fini & final \\
\hline gen & internal generation \\
\hline$h$ & heated \\
\hline$h p$ & heat pump \\
\hline ini & initial \\
\hline$I$ & primary side \\
\hline II & secondary side \\
\hline ind & individual \\
\hline $\min$ & minimum \\
\hline REFP & NIST Refprop (Reference Fluid Thermodynamic and Transport Properties) \\
\hline SH & space heating \\
\hline $\operatorname{surf}$ & surface \\
\hline$u c$ & uncompressible \\
\hline$u h$ & unheated \\
\hline vent & ventilation \\
\hline $1,1^{\prime}, 2,2^{\prime}, 3,3^{\prime}, 4$ & heat pump junction number \\
\hline \multicolumn{2}{|l|}{ Superscripts } \\
\hline $\mathrm{i}$ & auxiliary index \\
\hline $\mathrm{j}$ & day \\
\hline $\mathrm{t}$ & hour index \\
\hline
\end{tabular}




\section{Introduction}

Ground source heat pumps (GSHPs) are one the most recognized technologies by which the underground thermal energy storage (UTES) is realizable. GSHP systems use a small amount of electricity to extract large amounts of heat from the ground when heating of the human habitat is needed, and to store the excess thermal energy into the ground when cooling, on a cyclic basis. They constitute a very attractive solution for space heating (SH), space cooling (SC), and domestic hot water (DHW) in the residential sector, in particular for low energy houses [1]. However, the dissemination of the technology is very limited, and it is still under-used in the world [2]. The slow growth with respect to other renewable technologies can be attributed to non-standard system designs, high investment cost, limited number of knowledgeable people, and limited government policies [3]. As a consequence, recent research efforts to increase the expansion of GSHPs have been directed to develop new systems which can work from a combination of various heat sources such as ground and air [4] or ground and solar radiation [5]; or which provide a combination of various functions in a single machine, such as cooling and DHW [6], heating, DHW and simultaneous cooling and DHW [7] or heating and DHW [8]. This is the case of the multi-function monovalent inverterdriven water-to-water heat pump with a desuperheater, recently developed and characterized against variable climate and control conditions by the authors [9]. Moreover, the widespread adoption of GSHP systems can be stimulated by the development of prediction software tools capable of quickly providing results by which comparison with traditional solutions is possible.

Three main simulation blocks can be identified to accurately reflect the performance of a GSHP system of a low energy house as depicted in Fig.1:

- The house thermal demand block

- The ground simulation block

- The heat pump block 
Research in the literature, has concentrated in the first two blocks. Determination of the heating demand for homes is a subject extensively studied. Standard models and calculation methods [10, 11], new methodologies that take into account the thermal comfort $[12,13]$, and experimental evaluation of case studies [14] are available. With regard to the ground simulation block, recently theoretical and numerical models have been developed for both the vertical borehole [15-17] and the horizontal loop/slinky [18, 19] heat exchangers. However, the heat pump block has not been accurately addressed. Instead, equation-fitted models based on experimental results have been traditionally used on developed simulations which integrate the three blocks [20]. Two problems are identified with this approach. The first one is the limitation of applicability of equation-fitted models. If real climate conditions vary out of the range of application, the global simulation can give unreliable results. The second problem is that equations-fit models do not consider control parameters of the machine. Consequently, no evaluation on the control methodology of the GSHPs can be performed.

This paper will examine the application of a recently developed performance-oriented simulation in which control schemes of a monovalent inverter-driven water-to-water heat pump with a desuperheater can be evaluated. Special emphasis will be given to the heat pump block. In particular, the short term energy storage for DHW will be examined for a simple low energy house during heating season for two Japanese geographical conditions. Four control schemes for the production of DHW are proposed according to two tariff plans, from which comparison of performance between each strategy will be possible.

\section{Operation of the monovalent inverter-driven water-to-water heat pump with a desuperheater}

The monovalent heat pump presented uses an inverter-driven compressor and an electronic expansion valve to adjust its condensation and evaporation temperatures to constantly meet variable load conditions according to the thermal demand of a low energy house. Its component scheme is shown in Fig. 2. A Prepared by David Blanco, Katsunori Nagano and Masahiro Morimoto 
variable flow rate pump is used in the desuperheater to provide a user-fixed DHW outlet temperature. This DHW is then stored in a tank for later use. Six operating modes can be configured with this system, as related in Table 1. In heating mode, as shown in Fig. 2a, Heat is extracted in the primary side by configuration of the three way valves and activation of pump $B_{I}$. When only space heating is necessary (mode 1), pump $B_{D H W}$ is turned off while pump $B_{I I}$ is turned on. When only DHW is necessary (mode 2 ), $B_{I I}$ is turned off and $B_{D H W}$ is turned on. When both services are demanded (mode 3), both pumps operate. The four-way valve in the heat pump is reversed for cooling mode, as shown in Fig. 2b. The three way valves in the secondary side are configured to service the fan coil unit which extracts heat of the house when $B_{I I}$ is operated. This heat can be stored it in the ground (mode 4), heat the DHW (mode 5) or do both at the same time (mode 6).

\section{Simulation development}

\subsection{Simulation environment of the monovalent inverter-driven water-to-water heat pump with a}

\section{desuperheater}

A unique steady-state vapor compression refrigeration cycle simulation for a monovalent inverter-driven water-to-water heat pump with a desuperheater was recently developed by the authors [21]. The program, which was validated by comparison of simulated and experimental results on a constructed prototype machine, was based on the geometrical and thermodynamic characteristics of each main component of the heat pump shown in Fig. 2. Fast adaptive models were developed for the heat exchangers while block models were used for the compressor and expansion valves. A multivariable error minimization algorithm was used to obtain convergence. With it, the space heating or cooling capacities, domestic hot water generation heat transfer and compressor power can be determined according to the set climate conditions and the user-specified control parameters of the system. The simulation is performance-oriented, meaning that no thermodynamic assumptions are made besides the existence of a superheating degree at the compressor input, so that the simulation can be presented to the user as a black-box, exactly as would happen in a real machine. Additionally, the different operation modes can be simulated.

Prepared by David Blanco, Katsunori Nagano and Masahiro Morimoto 
Simulated operation maps of the highest COP according to the target climate conditions shown in Table 2 were developed for each heating operation mode. Spline-fit interpolation of the results for each interest performance parameter in modes 1 and 3 are shown in Fig. 3 and 4. Using these maps, the performance of the heat pump can be understood. If the system works in mode 1, the operation frequency can be determined from Fig. $3 b$ in order to match a fixed heating demand for a specific ground temperature condition. From the frequency and ground inlet temperature, the COP, $Q_{e}$ and $W_{e l}$ can be determined from Figs. 3a, 3c and 3d. A similar procedure can be applied working in mode 3 by using Fig. 4. Although spline-fit extrapolation outside the target region is possible, it is preferable to extend the mapping by using the simulation until the entire region is covered, and then construct the interpolation. In this way, it is maintained the validity of the simulation results.

\subsection{Subject low energy house and simulation conditions}

A single room detached low energy house was analyzed during heating season for the Japanese cities of Sapporo (average temperature $8.6^{\circ} \mathrm{C}, 2,638^{\circ} \mathrm{C}$-day) and Tokyo $\left(15.6^{\circ} \mathrm{C}, 900^{\circ} \mathrm{C}\right.$-day). Table 3 presents the main characteristics of the subject low-energy house. Several assumptions have to be made. While it is well known among HVAC designers that there a range of temperatures in which comfort is established for each season, for this case the interior temperature was kept at a constant temperature of $21{ }^{\circ} \mathrm{C}$. Additionally, analysis steps of one hour were assumed. As a consequence, steady state could be assumed; therefore the heat balance in the house can be simplified as shown in Eq. (1):

$$
C_{p, a i r} \rho_{a i r} V_{a i r} \frac{d T_{a}}{d t}=Q_{h p}+Q_{\text {solar }}+Q_{\text {gen }}-Q_{\text {house }}
$$

where $Q_{\text {house }}$ represents the heat loss of the house:

$$
Q_{\text {house }}=\sum Q_{\text {wall }}+\sum Q_{\text {window }}+Q_{\text {roof }}+Q_{\text {floor }}+Q_{\text {vent }}
$$

The heat transfer in each surface is calculated from Eq. (3) while the ventilation heat transfer is calculated from Eq. (4): 


$$
\begin{gathered}
Q_{\text {surf }}=U_{\text {surf }} A_{\text {surf }}\left(T_{\text {in }}-T_{\text {out }}\right) \\
Q_{\text {vent }}=C_{\text {air }} \rho_{\text {air }} G_{a i r}\left(T_{\text {in }}-T_{\text {out }}\right)
\end{gathered}
$$

The pattern for internal generation was assumed to be the same for every day, and was taken based on the International Energy Agency (IEA) Heat pump Program's Annex 32 [1]. Although the simulation can model a variable ground inlet temperature $T_{e l}$, as shown in Figs. 3 and 4, in this research this temperature was assumed to be $0^{\circ} \mathrm{C}$ for Sapporo and $5^{\circ} \mathrm{C}$ for Tokyo. Additionally, the ventilation rate was assumed to be 0.5 air volume per hour. DHW is stored at $65^{\circ} \mathrm{C}$ in a tank with maximum capacity of 460 liters. The DHW consumption temperature is taken as $42{ }^{\circ} \mathrm{C}$ by mixing the water coming from the tank with tap water. Outdoor temperature, solar radiation and tap water temperature were taken from the Expanded Amedas Weather Data [22].

Two electricity pricing plans were examined. In order to reduce the peak city demand of electricity, utility companies in Japan and other countries recently started to offer selective pricing plans according to the time of usage. The e-time 3 plan offered by Hokkaido Electric Power Co., Inc [23] was selected for comparison. In this plan, pricing is divided in three. Between $10 \mathrm{pm}$ and $8 \mathrm{am}$ is the lowest fare (0.07 EUR kWh), and between $1 \mathrm{pm}$ and $6 \mathrm{pm}$ is the highest fare (0.30 EUR kWh). In between hours, a price of $0.23 \mathrm{EUR} \mathrm{kWh}$ is charged. Additionally, the flat-rate plan was examined with a tariff of 0.18 EUR kWh.

\subsection{Short term energy storage control schemes}

Taking advantage of the pricing plans, four operation schemes of the compact heat pump with a desuperheater were explored for the control of the short-term DHW storage tank, as depicted in Fig. 5.

- Scheme 1: (e-time 3 tariff) DHW is produced as a by-product of SH: The heat pump operates in mode 3 only when $\mathrm{SH}$ is required. When the DHW requirement is met for the day, the heat pump switches to mode 1 . The heat pump is operated at the highest COP for the particular climate 
conditions. If the DHW demand cannot be met, an electric heater with efficiency of 0.97 is used to cope with the remaining demand.

- Scheme 2: (e-time 3 tariff) DHW is produced as a by-product of SH only during the lowest night tariff hours: The heat pump works in mode 1 during the day and switches to mode 3 during the night. When the DHW requirement is met, the heat pump switches to mode 1 . The heat pump is operated at the highest COP for the particular climate conditions. If the DHW demand cannot be met, the electric heater is used as in scheme 1.

- Scheme 3: (e-time 3 tariff) DHW production is managed during the night according to the settled DHW requirements and consumption pattern established. When the DHW requirements are met, it switches to mode 1 . When no SH requirements are needed it switches to mode 2 until the DHW demand is met. The heat pump is operated at the highest COP for the particular climate conditions; however, it may happen that in those conditions the DHW demand cannot be met. In such a case, the heat pump uses its variable load capacities to adjust the control parameters in order to cover the necessary demand. This will be made clear in section 3.4 In this case, the machine does not operate at the highest COP.

- Scheme 4: (flat-rate tariff) The characteristics of the control are the same as for Scheme 3, except that DHW production is managed during all the day

The algorithms are depicted in Fig. 6 in which each scheme can be easily followed.

\subsection{Mode 3 control adjustment algorithm}

Notice that the operation maps are constructed by identifying the highest COP for each climate condition. This is the traditional operation when only one service, either SH or DHW, is needed. However, when both services are demanded, there are two options. The first one is to operate the machine to cover the $\mathrm{SH}$ demand at the highest COP, and produce DHW as a by-product, as in schemes 1 and 2. But in this case, there is no knowledge of the amount of DHW produced. In fact, there is no certainty that the produced 
DHW will cover the demand, and electric heaters need to be utilized to account for missing DHW. This operation mechanism is used for Schemes 1 and 2.

The second option is to fulfil simultaneously both the SH and the DHW demand. While the SH demand can be calculated according to the target low energy house, the DHW has to be taken from specific conditions depending on the geographic locations and cultural customs. The Japanese DHW consumption pattern was taken from Yamamoto et al. [24], and applied for this study. The average DHW demand for a day per year can be observed in Fig. 7. Using this pattern, the necessary average daily amount of DHW produced can be calculated. The total DHW needed for a day $j$ is given by Eq. (5):

$$
V_{\text {total }}^{j}=\sum_{i=0}^{24} G_{d}^{j, i}
$$

where $G_{d}$ is the average consumption rate per hour at the target storage temperature $T_{d 2}$. For a given time $t$ inside the low tariff hours, two volumes are defined to keep track of the DHW that has been produced as shown by Eq. (6):

$$
\begin{aligned}
& V_{u h}^{j, t}=V_{u h}^{j, t-1}-G_{d}^{j, t-1} \\
& V_{h}^{j, t}=V_{h}^{j, t-1}+G_{d}^{j, t-1}
\end{aligned}
$$

When peak demand occurs, there is a risk of running out of DHW. To avoid this, the DHW demand should consider not only to fill the tank at $T_{d 2}$ within the time frame selected (low tariff hours for scheme 3 , while 24 hours for scheme 4), but to be able to supply the necessary DHW for the following determined time period. According to this, the minimum heating demand is given by Eq. (7):

$$
Q_{d \text { min }}^{j, t}=\frac{G_{d}^{j, t} \rho_{\text {water }} C_{p, \text { water }}\left(T_{d 2}-T_{d 2}{ }^{j, t}\right)}{3600}+\frac{\left(V_{u h}^{j, t}-G_{d}^{j, t}\right) \rho_{\text {water }} C_{p, \text { water }}\left(T_{d 2}-T_{d 2}{ }^{j, t}\right)}{3600 \cdot\left(t_{\text {fini }}-t+1\right)}
$$

The first component in the right side of Eq. (7) represents the minimum DHW demand for the next hour, while the second component represents the remaining minimum DHW demand to cover entirely the requirements for day $j$. Therefore the heat pump should be able to cope with the SH demand $Q_{S H}$, and the determined DHW demand $Q_{d m i n}$ for that particular time. 
For operation mode 3, the relationship between $Q_{c}$ and $Q_{d}$ can be plotted for each frequency as shown experimentally in Fig. 8a. Fig 8b shows the possible situation found when $Q_{d \min }$ is higher than the provided $Q_{d}$ at the highest COP. In order to fulfill both services, the inverter-driven compressor must increase its operation frequency and close the expansion valve step to increase the condensation temperature and shift some of $Q_{t}$ to $Q_{d}$. By doing so, the COP is reduced, but both of the services are fulfilled. A root finding algorithm [25] is applied to find the working frequency at which both services can be fulfilled. From this frequency, the other parameters can be derived. The control algorithm is presented in Fig. 9.

\section{Results and discussion}

The heat pump simulation platform was programmed in EES software, while Matlab was used for the thermal analysis of each scenario. This section will first present the results of the simulation for the coldest day of the year for each location and for each control scheme. Then, a long term examination for the heating period of the year for both locations will be discussed.

\subsection{Coldest day examination}

The SH and DHW demands were calculated for the target house during an entire year. The information from the coldest day was extracted, and it is shown in the stacked column Fig. 10. The total SH demand was of 145.2 and $83.2 \mathrm{kWh}$ for Sapporo and Tokyo, respectively. The target amount of $\mathrm{DHW}$ at $42^{\circ} \mathrm{C}$ for both locations was of $405 \mathrm{~L}$.

\subsubsection{Scheme 1}

Scheme 1 was run for the examined period, and its results are plotted in Fig. 11. It is observed that the system can fulfill the SH demand for both locations, and that the COP of the system stays within 3 and 5 for both locations. Additionally, it is evident that that the heating demand is much higher for Sapporo, which has a climate very similar to central Europe or southeast Canadian climates. Having a higher heating output

Prepared by David Blanco, Katsunori Nagano and Masahiro Morimoto 
and operating the machine in mode 3 yields also a higher DHW output. As a result, the DHW thermal requirements can be met for Sapporo, without need to produce DHW the whole day to cope with the DHW demand. This is not the case for Tokyo, where the backup electrical heater needs to be used, despite of producing DHW during the complete day. The situation in the DHW tank reflects the above effect. The peak storage of DHW reaches the $200 \mathrm{~L}$ and $120 \mathrm{~L}$ in Sapporo and Tokyo respectively. The lower temperature of the tap water in Sapporo influences the peak storage of DHW, as an additional amount of hot water stored is needed when the tap water temperature is reduced.

\subsubsection{Scheme 2}

Because of the high SH demand, the system exhibits a similar behavior using scheme 2 to the one obtained for scheme 1 in the case of Sapporo, as shown in Fig. 12. However, the condition of producing DHW only during the low tariff hours impacts directly the production of DHW in Tokyo. Despite of having a high COP, the electrical heater has to be used during most of the night hours in order to cope with the DHW demand, at a relatively high power. It is also observed that the tank size needs to be incremented for both locations, reaching $234 \mathrm{~L}$ for Sapporo and $193 \mathrm{~L}$ for Tokyo (using the backup heater).

\subsubsection{Scheme 3}

Scheme 3 shows a slightly different performance for Sapporo than in the previous schemes, as shown in Fig. 13. However, the COP drops, as expected, when the control adjustment is applied. This effect is even more dramatic for Tokyo, where the COP varies from as much as 4.3 to as low as 2.21 . What is more interesting is that by applying this control, the totality of DHW can be covered in both locations. This eliminates completely the need of the electrical heater. However, as the system operates at a lower performance, a higher electrical consumption might happen. The peak storage of DHW is of 224 and 193 L for Sapporo and Tokyo, respectively.

Prepared by David Blanco, Katsunori Nagano and Masahiro Morimoto 


\subsubsection{Scheme 4}

Scheme 4 liberates the restriction of producing DHW during the low tariff hours; however in the case of Sapporo almost the entire demand of DHW can be covered during the nighttime, as observed in Fig. 14. The COP is in this case slightly higher than in the scheme 3. In Tokyo, the control adjustment permits to cope with the DHW demand at a lower heating output of the system during three fourths of the day. It is interesting the shift of the peak DHW storage hours. The shift is markedly visible for Tokyo, where the DHW demand is covered only until $6 \mathrm{pm}$. For this scheme, the maximum storage occurs at 252 and $207 \mathrm{~L}$ for Sapporo and Tokyo, respectively.

\subsubsection{Comparison of schemes}

The performance variables of these four schemes was gathered and organized in Table 4. For Sapporo, schemes 1 and 3 provide the lowest cost. However, scheme 1 presents a slightly lower electrical consumption. As a consequence, there is a tradeoff between these two desirable conditions. Either the system works at the lowest cost or the lowest electrical consumption. Additionally, scheme 2 has the highest electrical consumption among the four, and produces DHW in excess. Despite of this, it is cheaper than scheme 4, which confirms the advantage of the control by using the e-time 3 tariff plan over the flat-rate one. Finally, it is observed that the average COP does not vary greatly between the four schemes.

In the case of Tokyo the same phenomenon occurs: schemes 1 and 3 provide the lowest cost, despite of using the backup heater in scheme 1. However, both schemes practically show the same electrical consumption. In this case, it is scheme 4 who positions itself with the lowest electrical consumption. Unfortunately, it also has the highest cost, being almost the same as the cost of scheme 2, which also makes use of the backup heater. The tradeoff between the lowest cost and the lowest electrical consumption is Prepared by David Blanco, Katsunori Nagano and Masahiro Morimoto 
maintained. Without considering the backup heaters, the average COP shows little variation among the schemes.

\subsection{Seasonal examination}

The analysis during the heating season for both locations is presented in Table 5. Scheme 3 shows for Sapporo the lowest cost, being slightly inferior to scheme 1. This shows a better management of low demand over the other schemes. It is observed that scheme 1 uses the backup heater. This obeys the fact that when the temperature gets warmer, less DHW is produced, and not all of the DHW can be fulfilled. On the other hand modes 3 and 4, which incorporate the control adjustment algorithm, don't make use of it and are able to meet both thermal demands simultaneously. Regarding the lowest electrical consumption, modes 1 and 4 practically have the same performance. Scheme 2 shows the highest cost and highest electrical consumption, evidencing the need of a better control strategy.

In Tokyo, scheme 1 clearly shows the lowest cost and lowest electrical consumption among the four schemes. This follows the fact that at the examined conditions, the matching of the system with the demand is almost perfect, and it can cover almost entirely the production of DHW at a higher COP. As a consequence, on the long run it outperforms the other schemes through the advantage of the flexible pricing plan. It comes as no surprise that the second lowest cost is achieved by scheme 3 , which takes full advantage of the pricing plan. As a consequence, it has a larger electrical consumption than scheme 4, which is second in electrical consumption. As in the case of Sapporo, scheme 2 has the highest cost and highest electrical consumption.

The previous results manifest three important characteristics. 
- First, producing DHW as a by-product of SH only during the night hours, as in scheme 2, has the worst performance in terms of management of the resources. During the coldest day DHW is produced in excess for Sapporo while it is not enough for Tokyo. During the seasonal analysis, more than half of the DHW has to be produced for both locations using the backup heater, resulting in its high price.

- Second, the control schemes taking advantage of the flexible tariff plan exhibit lower cost to the end user, although it might not always provide the lowest electrical consumption. In Sapporo, scheme 3 showed the lowest seasonal cost while for Tokyo it was scheme 1.

- Third, among the schemes analyzed it is not possible to have for Sapporo the lowest electrical consumption and lowest cost at the same time. This was possible for Tokyo by choosing scheme 1 .

The importance of an appropriate control on monovalent heat pump systems is clearly evidenced from the previous analyses. Moreover, on any xTES developed, control development and its simulation should provide ultimately insight into the real performance of the technology.

\section{Conclusions}

A new simulation on a monovalent inverter-driven water-to-water heat pump with a desuperheater has been successfully applied to a subject low energy house during a Japanese representative heating season. The simulation permits to develop control schemes according to the operation modes of the system, in order to compare desired performance parameters, showing great flexibility.

Four operation schemes of the system were evaluated. In the first scheme, DHW was produced at the highest COP only when SH was necessary. In the second one, DHW was produced at the highest COP during the period of lowest electricity cost, only when SH was necessary. In the third scheme, both SH and DHW are managed by use of the control parameters, not necessarily at the highest COP. DHW is produced only during the lowest tariff hours. The fourth scheme is the same as the third one, except DHW is produced 
according to the DHW demand during the whole day. The first three schemes used a flexible electricity tariff while a plain tariff was applied to the fourth one.

Several interesting conclusions were extracted from the study as follows.

1. It was demonstrated through the seasonal and daily analyses that the inverter-driven compressor and expansion valve control enables to manage the thermal load continuously, without using electrical backup heaters, as in schemes 3 and 4 .

2. However, due to the specific thermal demands of each site, no unique control scheme is suited for both geographical locations. As a consequence the final control installed on a system should be flexible in order to adapt to the thermal demand of that particular site.

3. The size of the short term DHW storage tank is determined by each operation scheme according to the specific thermal demand conditions.

4. Scheme 2 showed the worst economic and energetic performance, due to the absence of any DHW management control, and the limited time to produce DHW.

5. Schemes 1 and 3, which used the flexible tariff plan, have a lower cost, although they might not always provide the lowest electrical consumption. In particular, for the case of Sapporo a tradeoff was observed between these two desirable conditions. Scheme 3 showed the lowest cost while scheme 1 exhibited the lowest electrical consumption.

Through this study, the importance of simulation and control to properly manage any xTES is evidenced.

\section{Acknowledgements}

The authors would like to thank Sunpot Co. Ltd. for the development of the prototype and continuous support during the project, as well as interesting discussions and support from Ph.D. Ahmad Al-Mallahi and Ph.D. Fayna García-Martín. The financial support from the Ministry of Education, Culture, Sports, Science and Technology of Japan is deeply appreciated.

Prepared by David Blanco, Katsunori Nagano and Masahiro Morimoto 


\section{References}

[1] Carsten W. IEA HPP Annex 32 Final report IEA HPP Annex 32 Economical heating and cooling systems for low energy houses -Project outline and summary of main results.

[2] Chua KJ, Chou SK, Yang WM. Advances in heat pump systems: A review. Appl Energy 2010;87(12): 3611-24.

[3] Self JS, Reddy BV, Rosen MA. Geothermal heat pump systems: Status review and comparison with other heating options. Appl Energy 2012; in press, doi: 10.1016/j.apenergy.2012.01.048

[4] Nam Y, Ooka R, Shiba Y. Development of dual-source hybrid heat pump system using groundwater and air. Energ Buildings 2010;42(6): 909-16.

[5] Ozgener O, Hepbasli A. Performance analysis of a solar-assisted ground-source heat pump system for greenhouse heating: an experimental study. Build environ 2005;40(8): 1040-50.

[6] Shao S, Shi W, Li X, Ma J. A new inverter heat pump operated all year round with domestic hot water. Energ Convers Manage 2004;45(13-14): 2255-68.

[7] Ji J, Pei G, Chow T et al. Performance of multi-functional domestic heat-pump system. Appl energy 2005;80(3): 307-26.

[8] Stene J. Residential $\mathrm{CO}_{2}$ heat pump system for combined space heating and hot water heating. Int $\mathrm{J}$ Refrigeration 2005;28(8): 1259-65. 
[9] Blanco DL, Nagano K, Morimoto M. Experimental study on a monovalent inverter-driven water-towater heat pump with a desuperheater for low energy houses. Appl Therm Eng 2012; in press, doi: 10.1016/j.applthermaleng.2012.07.008

[10] ASHRAE, Energy Estimating and Modeling Methods, ASHRAE Fundamentals, 2001.

[11] SFS-EN ISO 13790 Thermal Performance of Buildings, Calculation of Energy Use for Space Heating, 2004.

[12] Ghiaus C. Free-running building temperature and HVAC climatic suitability. Energ. Buildings 2003;35(4): 405-11.

[13] Ghiaus C. Equivalence between the load curve and the free-running temperature in energy estimating methods Energ. Buildings 2006;38(4): 429-35.

[14] Takeda-Kindaichi S, Nagano K, Katsura T, Hori S, Shibata K. System performance of HVAC in a low energy house in the cold region of Japan. In: Proceedings of the 9th IEA Heat Pump Conference Zürich, May 20-22, 2008.

[15] Yavuzturk C, Spitler JD, Rees S. A transient two-dimensional finite volume model for the simulation of vertical U-tube ground heat Exchangers. ASHRAE Trans 1999;105(2): 465-74.

[16] Lee CK, Lam HN. Computer simulation of borehole ground heat exchanger for geothermal heat pump systems. Renew Energ 2008;33(6): 1286-96.

Prepared by David Blanco, Katsunori Nagano and Masahiro Morimoto 
[17] Katsura T, Nagano K, Takeda S. Method of calculation of the ground temperature for multiple ground heat exchangers. Appl Therm Eng 2008;28(14-15): 1995-2004.

[18] Li H, Nagano K, Lai Y. A new model and solutions for a spiral heat exchanger and its experimental validation. Int J Heat Mass Transfer 2012;55(15-16): 4404-14.

[19] Li H, Nagano K, Lai Y. Heat transfer of a horizontal spiral heat exchanger under groundwater advection. Int J Heat Mass Transfer 2012; in press, doi: 10.1016/j.ijheatmasstransfer.2012.06.089

[20] Nagano K, Katsura T, Takeda S. Development of a design and performance prediction tool for the ground source heat pump system. Appl Therm Eng 2006;26(14-15): 1578-92.

[21] Blanco DL, Nagano K, Morimoto M. Steady state vapor compression refrigeration cycle simulation for a monovalent inverter-driven water-to-water heat pump with a desuperheater for low energy houses. Int $\mathbf{J}$ Refrigeration 2012; in press, doi: 10.1016/j.ijrefrig.2012.07.005.

[22] Architect Institute of Japan, 2000. Expanded AMeDAS Weather Data, Architect Institute of Japan, Tokyo, Japan

[23] Hokkaido Electric Power Co., Inc web portal. Home electricity tariff plans (in Japanese); 2012. http://www.hepco.co.jp/userate/price/unitprice/unitprice02.html/ [cited 2012.07.24].

[24] Yamamoto N, Murakawa S, Takata H et al. A study on the loads of hot water consumption in houses with the hot water storage tank system-Part 1 . An analysis of the hot water usage and the loads of hot water 
consumption. In: Proceedings of the International Symposium Water Supply and Drainage for Buildings, Sydney, Nov. 8-10, 2010.

[25] Ridders, C. A new algorithm for computing a single root of a real continuous function. Trans. Circuits Syst. 1979;Vol. CAS-26 (11): 979-980. 


\section{List of Figures}

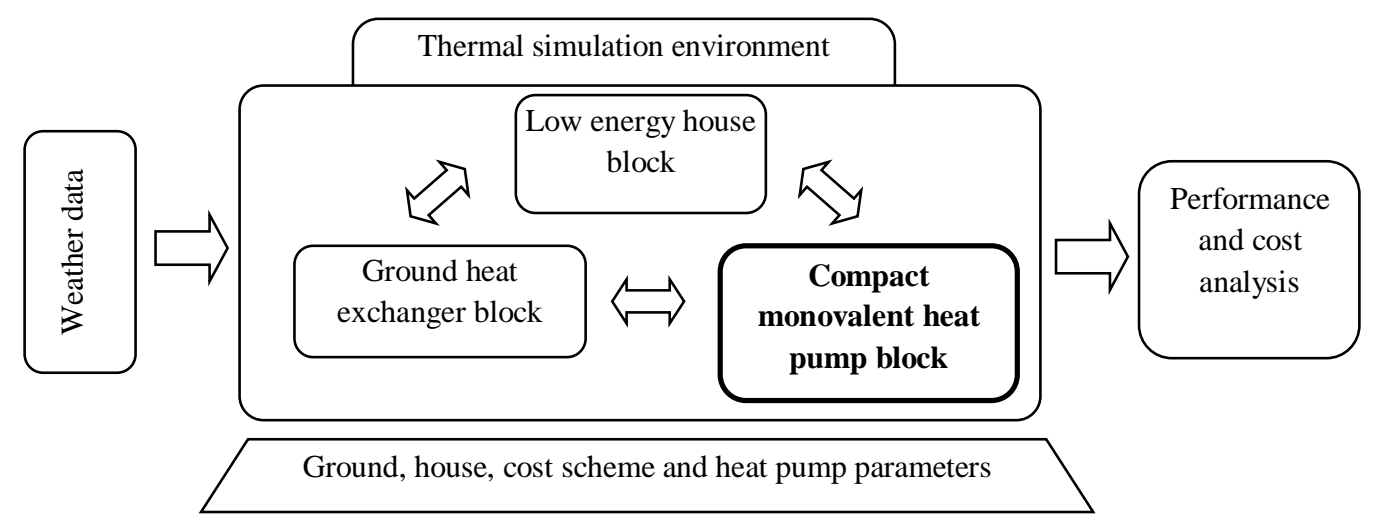

Fig. 1. Comprehensive simulation environment. 


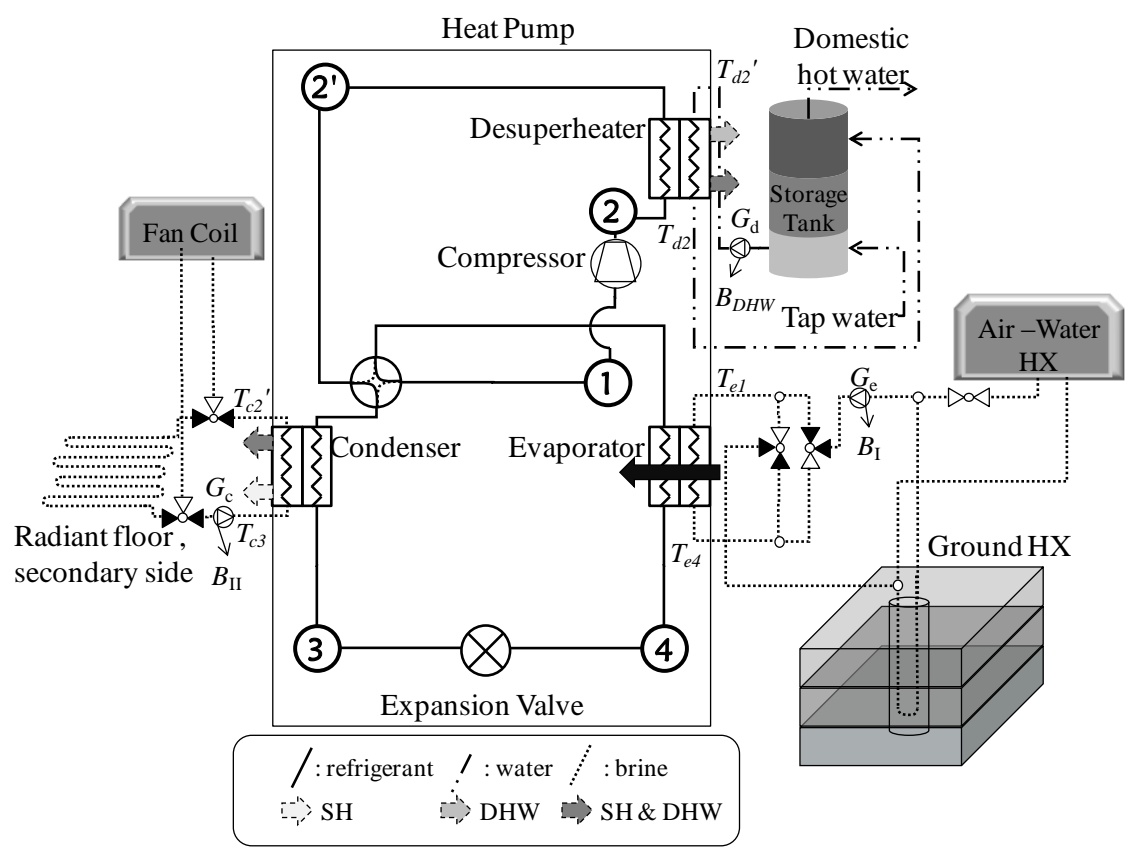

a) Heating modes

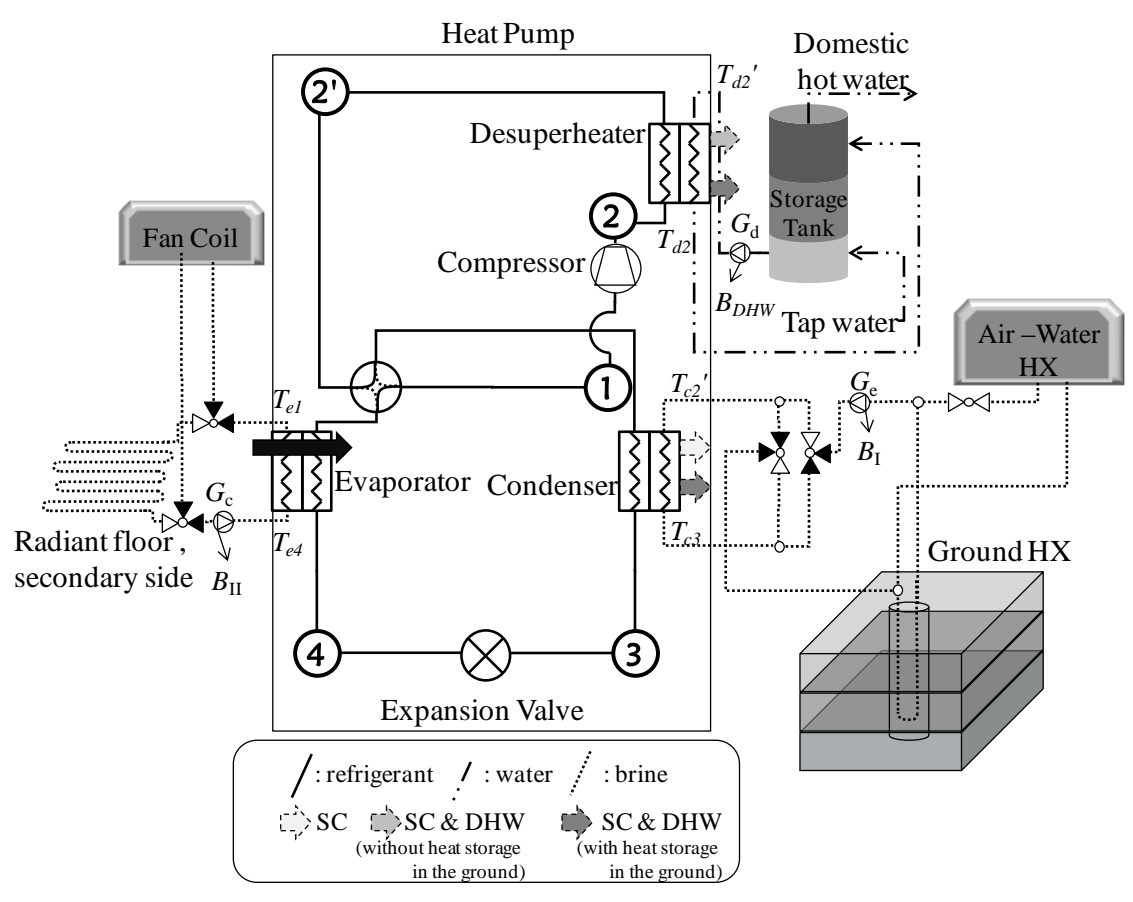

b) Cooling modes

Fig. 2. Compact GSHP with a desuperheater operation modes. 

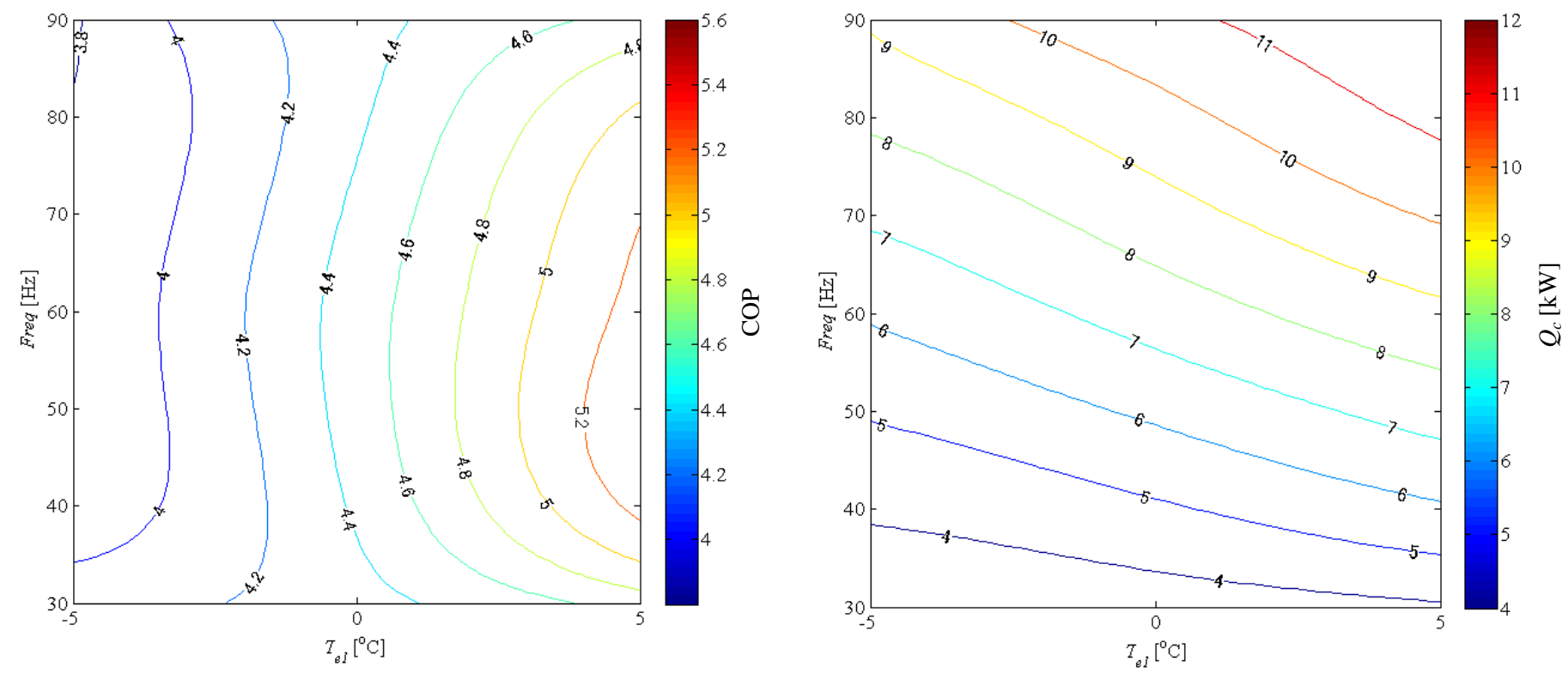

a) $\mathrm{COP}$

b) $Q_{c}$
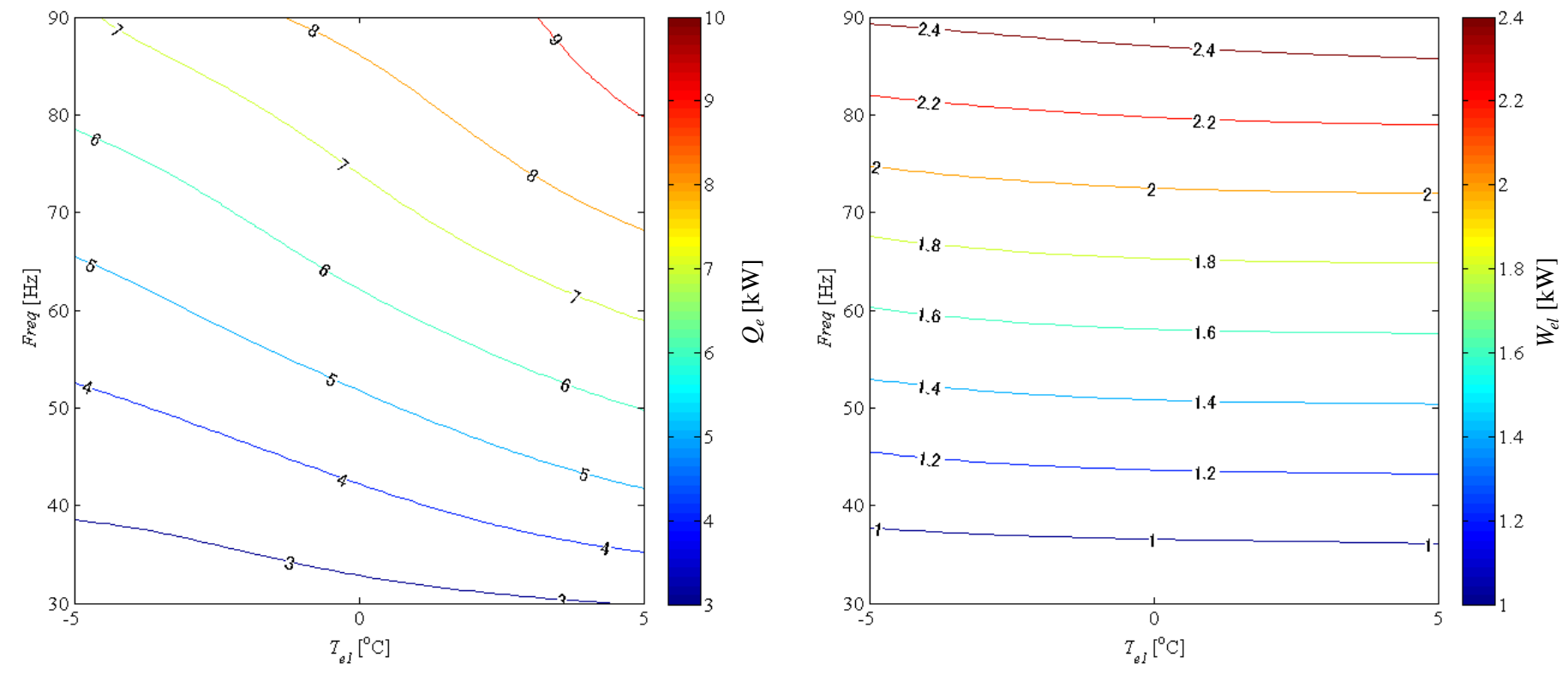

c) $Q_{e}$

d) $W_{e l}$

Fig. 3. SH only (mode 1) performance maps. 

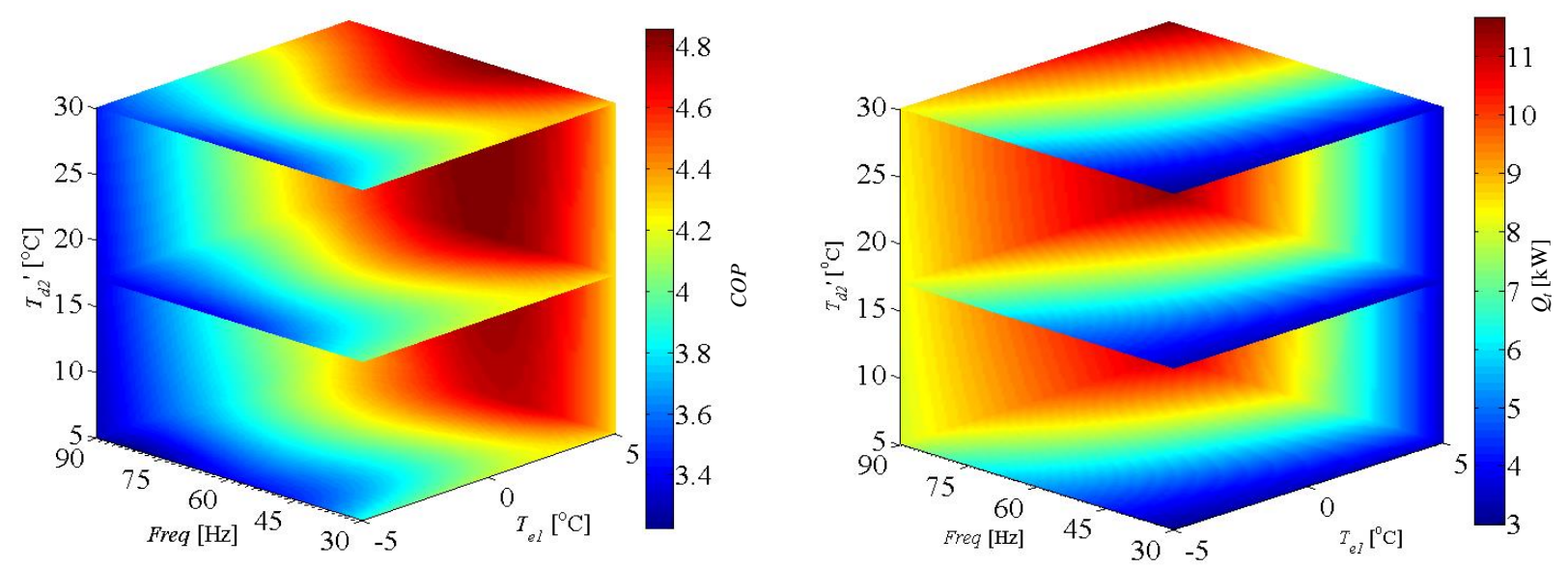

a) $\mathrm{COP}$

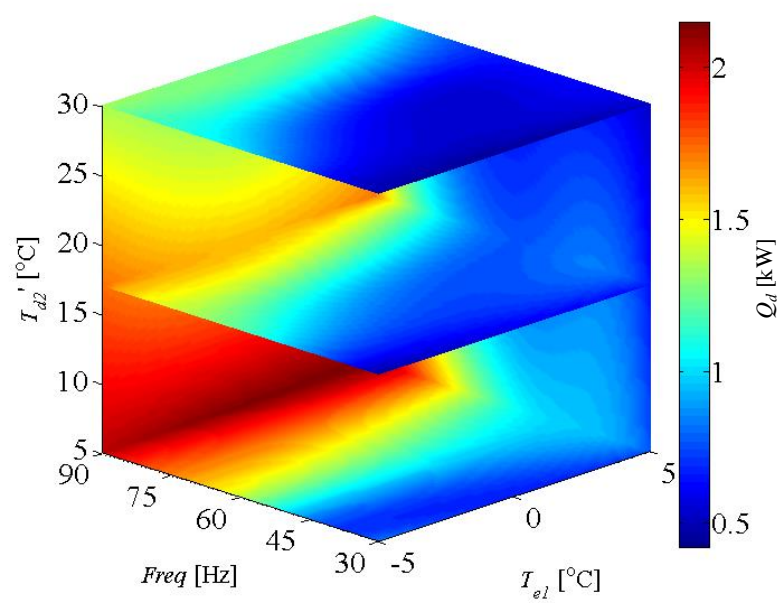

c) $Q_{d}[\mathrm{~kW}]$

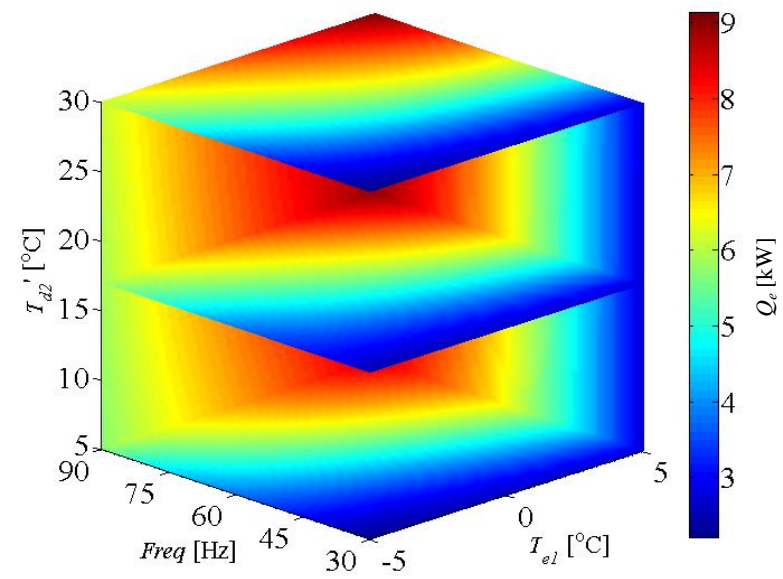

c) $Q_{e}[\mathrm{~kW}]$ b) $Q_{t}[\mathrm{~kW}]$

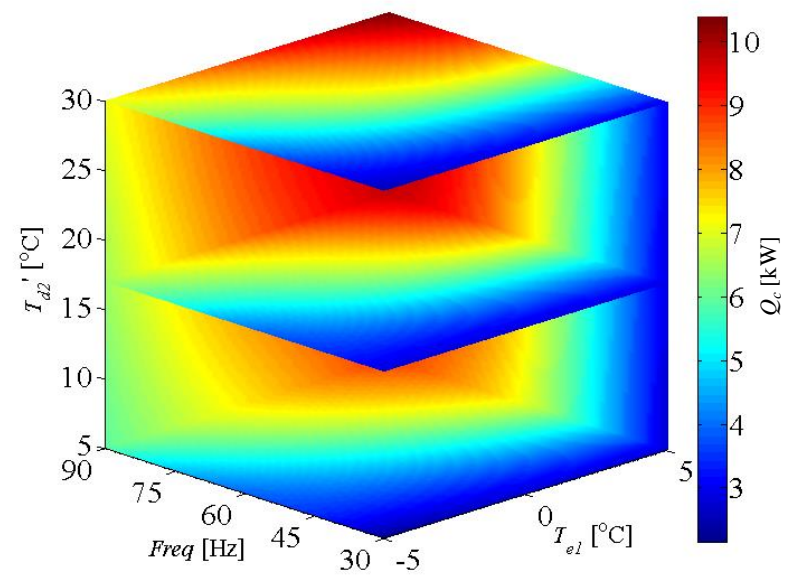

d) $Q_{c}[\mathrm{~kW}]$

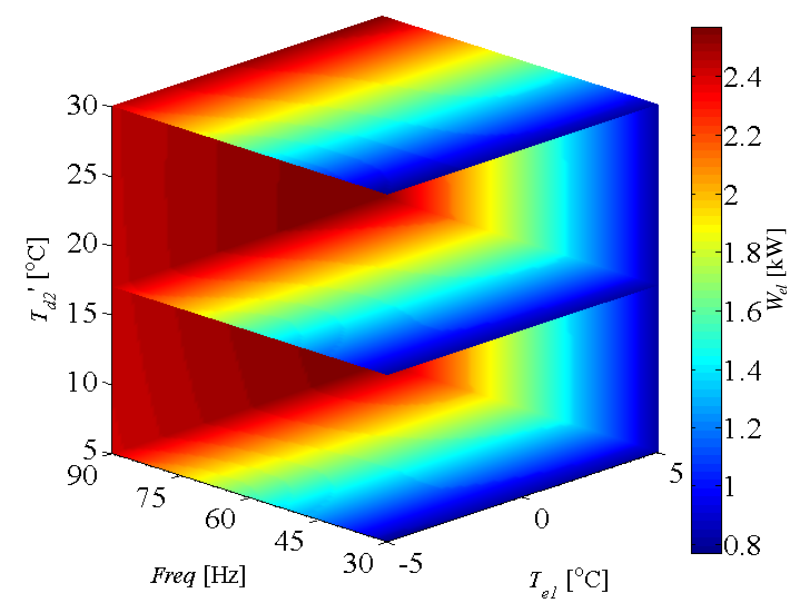

d) $W_{c}[\mathrm{~kW}]$

Fig. 4. SH\&DHW (mode 3) performance maps.

Prepared by David Blanco, Katsunori Nagano and Masahiro Morimoto 

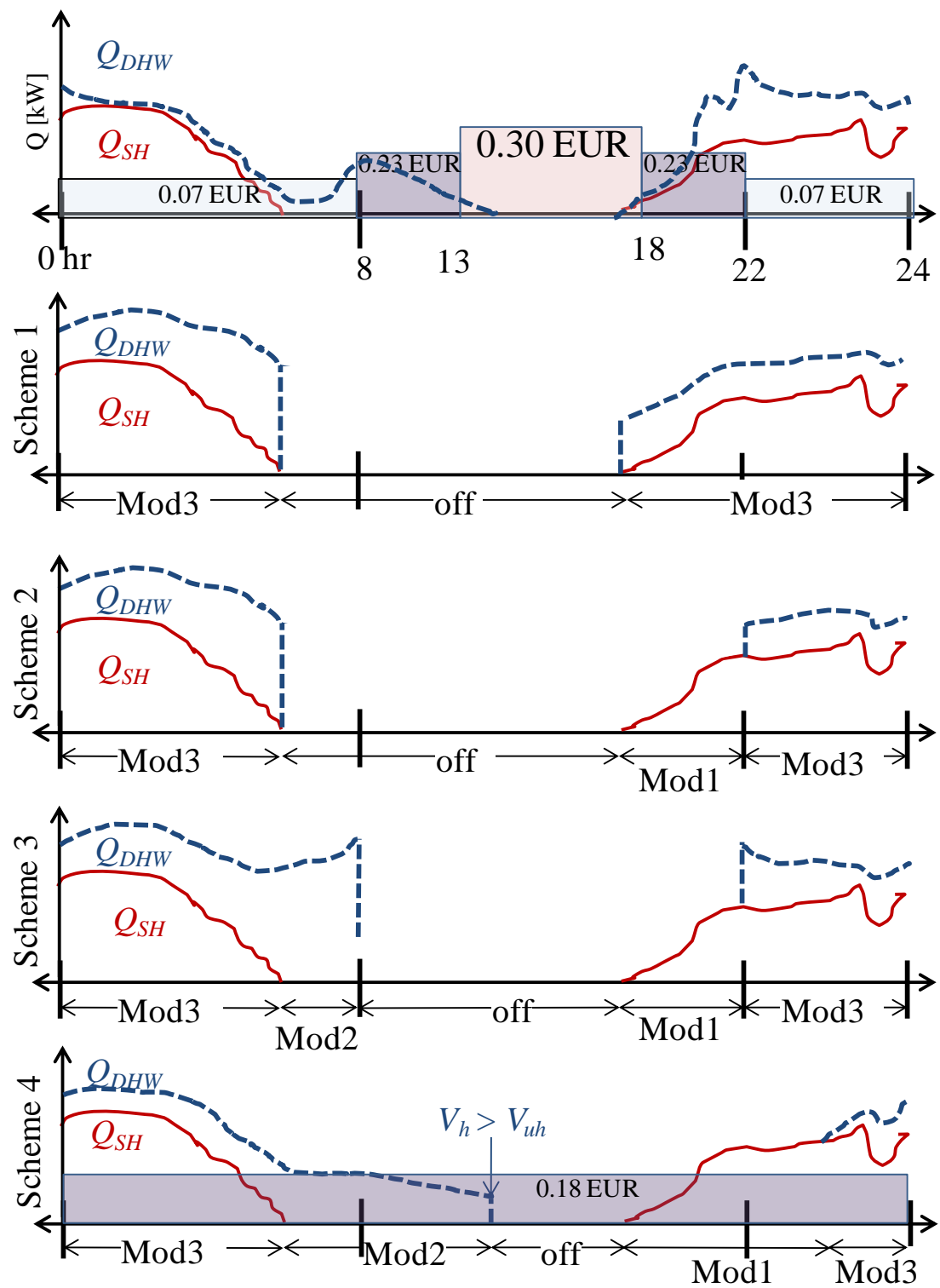

Fig. 5. Operation schemes of the compact GSHP with a desuperheater. Three-priced pricing plan is applied to schemes 1, 2 and 3, while fixed-priced plan is used for Scheme 4. 


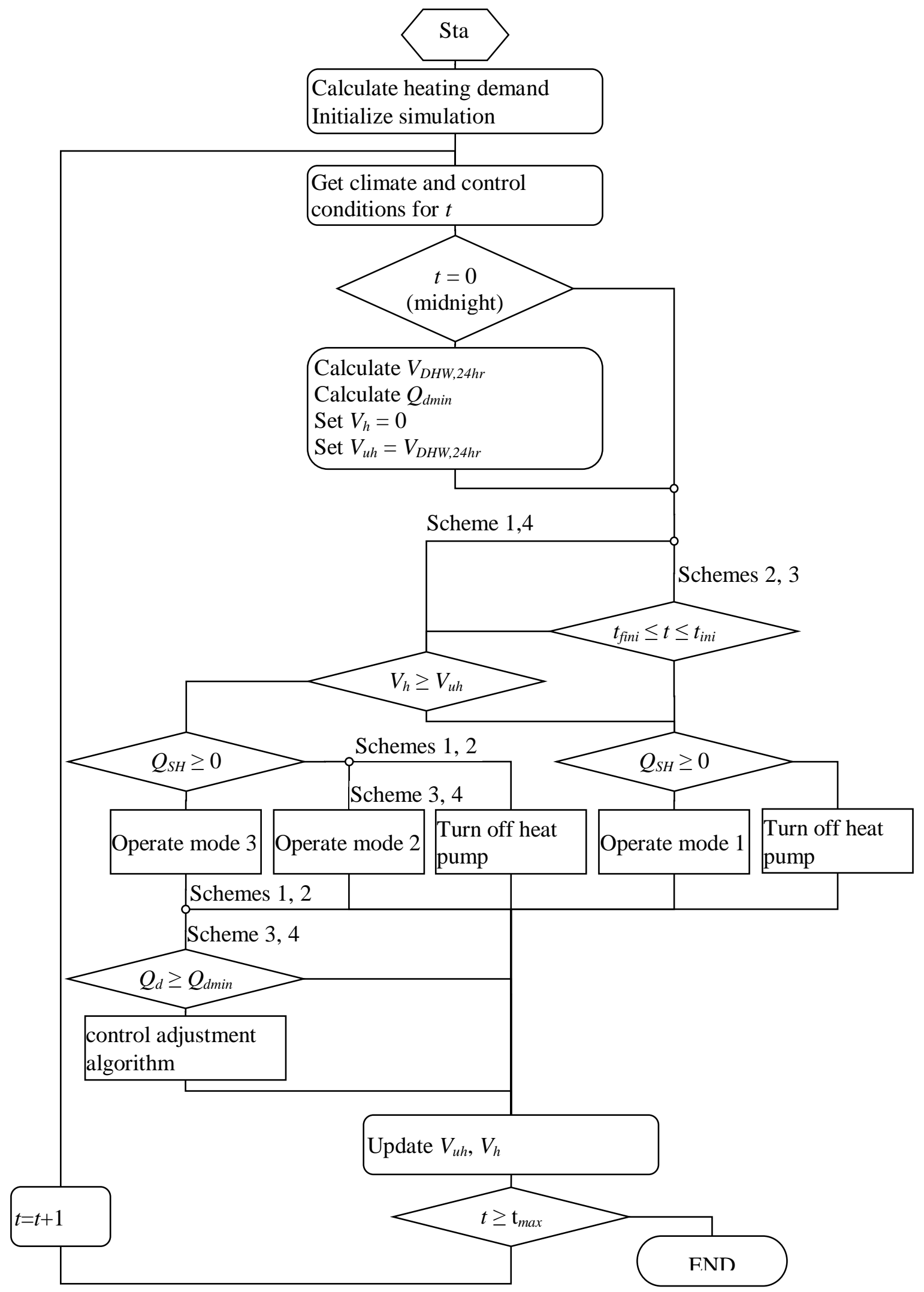

Fig. 6. Control algorithm for each proposed operation scheme

Prepared by David Blanco, Katsunori Nagano and Masahiro Morimoto 


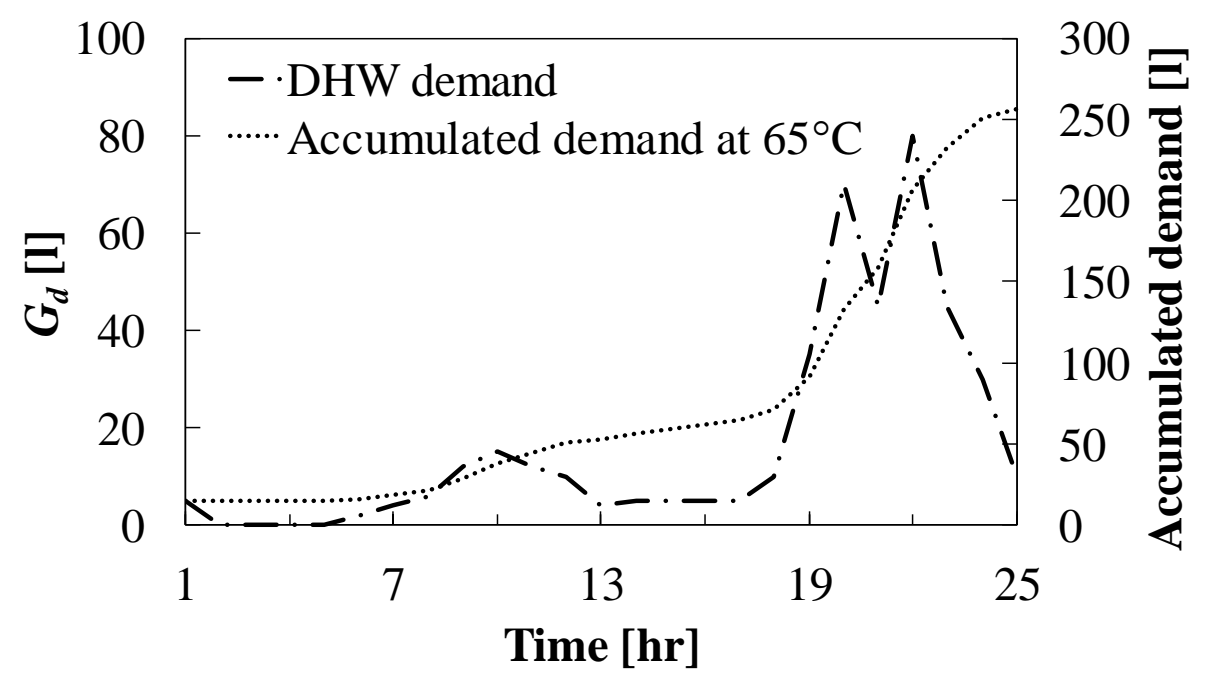

Fig. 7. Average DHW consumption pattern (based on Yamamoto et al. [24]). 


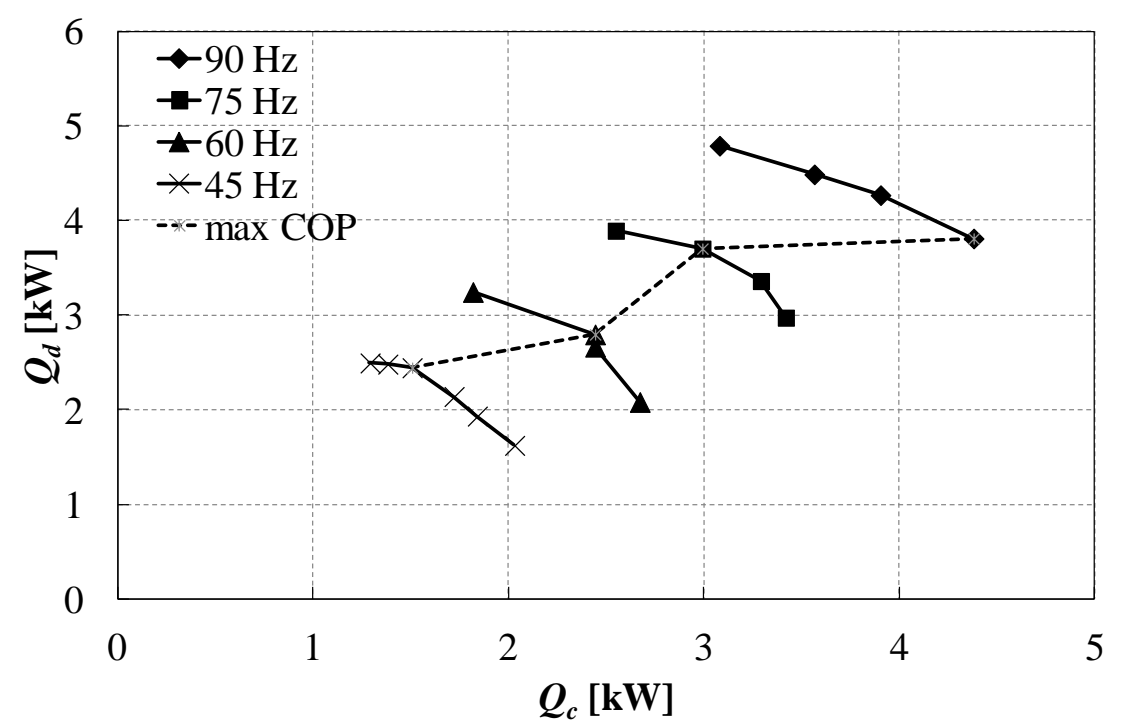

a. Experimental relationship between $Q_{c}$ and $Q_{d}\left(T_{e 1}=0^{\circ} \mathrm{C}, T_{d 2^{\prime}}=5^{\circ} \mathrm{C}, T_{c 2}=45^{\circ} \mathrm{C}\right)$

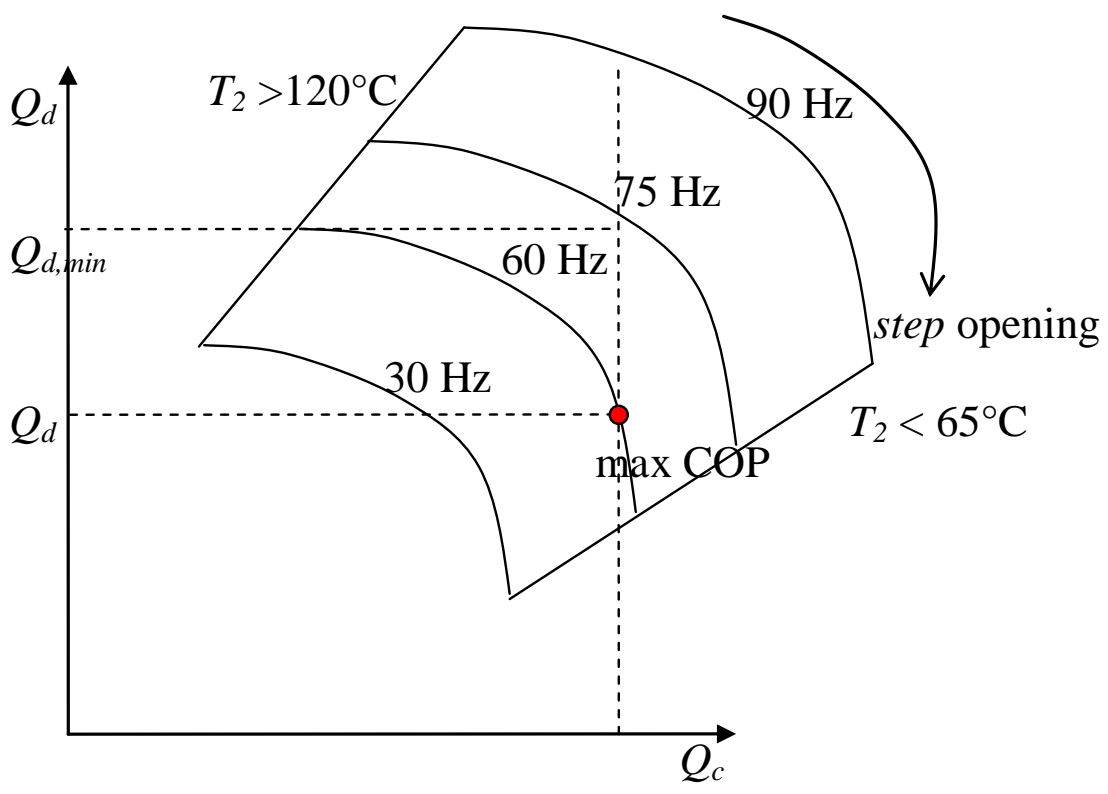

b. Modeled relationship

Fig. 8. Relationship between $Q_{c}$ and $Q_{d}$ for fixed climate conditions, according to the expansion valve opening and frequency variation.

Prepared by David Blanco, Katsunori Nagano and Masahiro Morimoto 


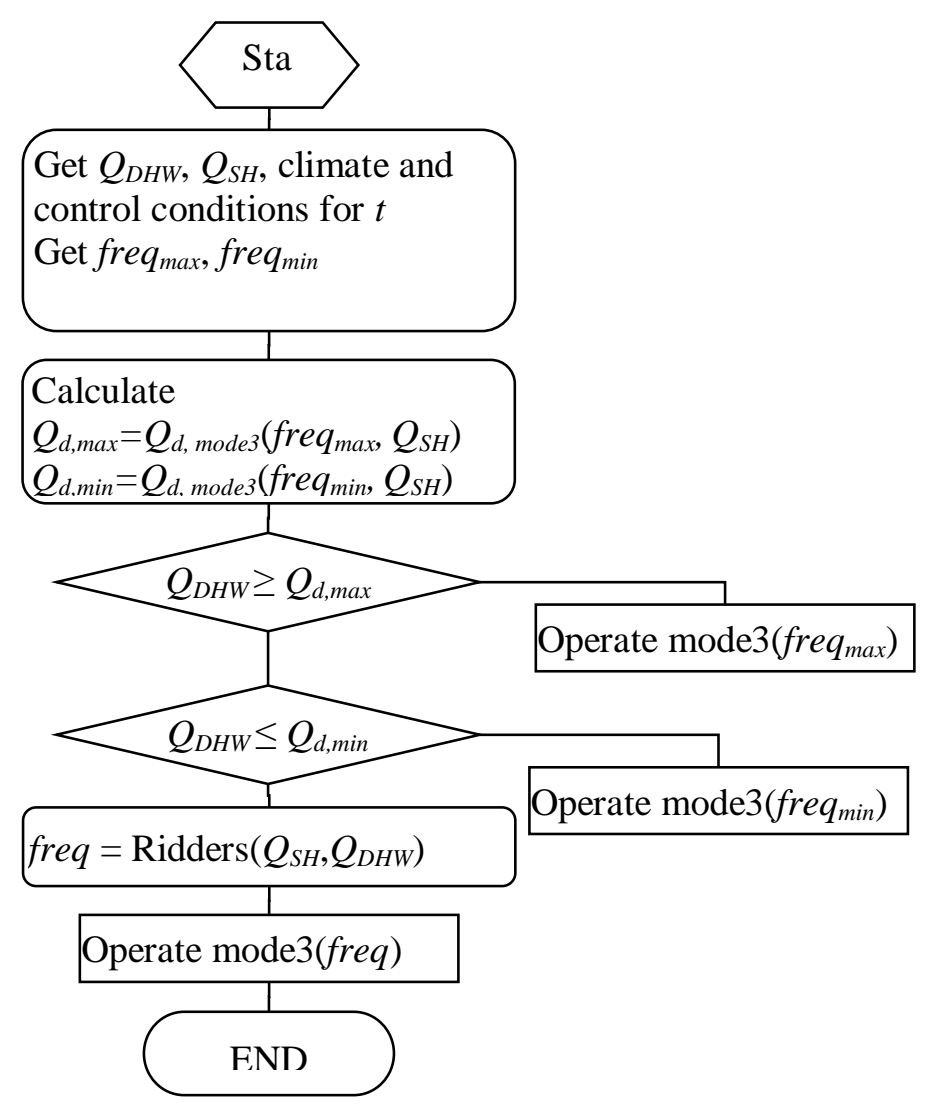

Fig. 9. Control adjustment algorithm 


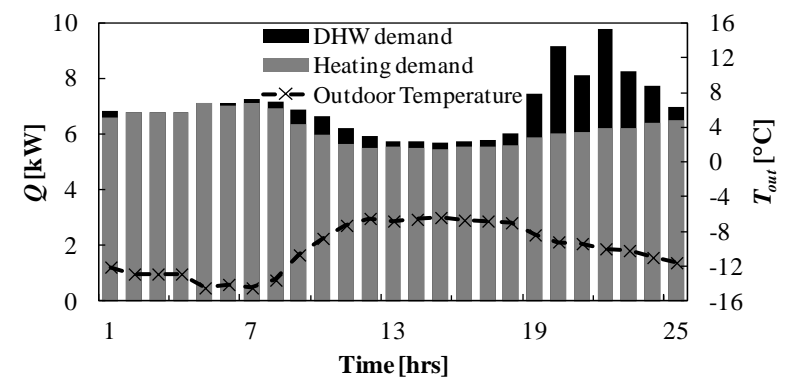

a. Sapporo

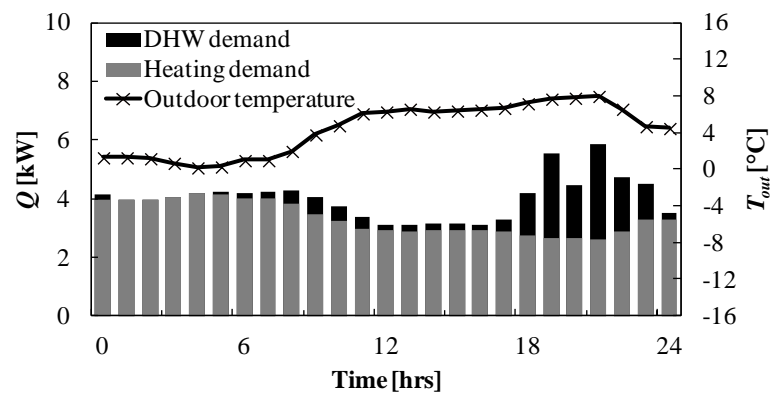

b. Tokyo

Fig. 10. Calculated $Q_{D H W}$ and $Q_{S H}$ during the coldest day of the year. 


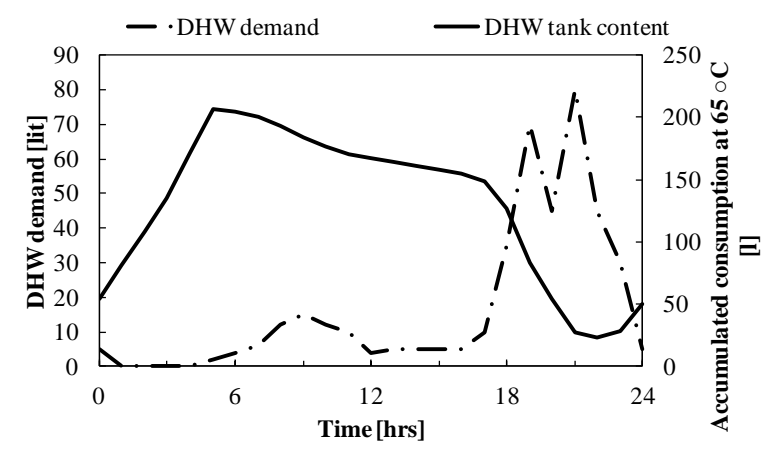

a. DHW tank, Sapporo

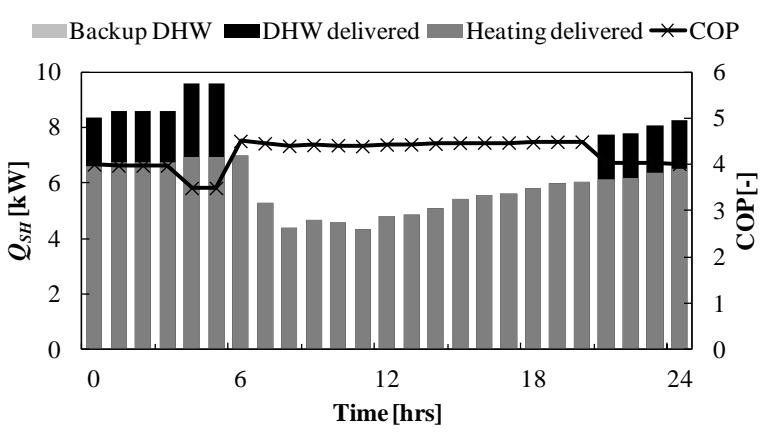

c. HP operation, Sapporo

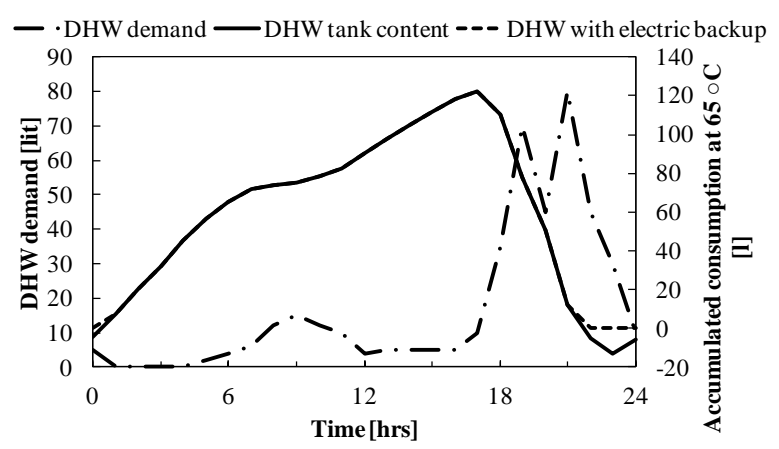

b. DHW tank, Tokyo

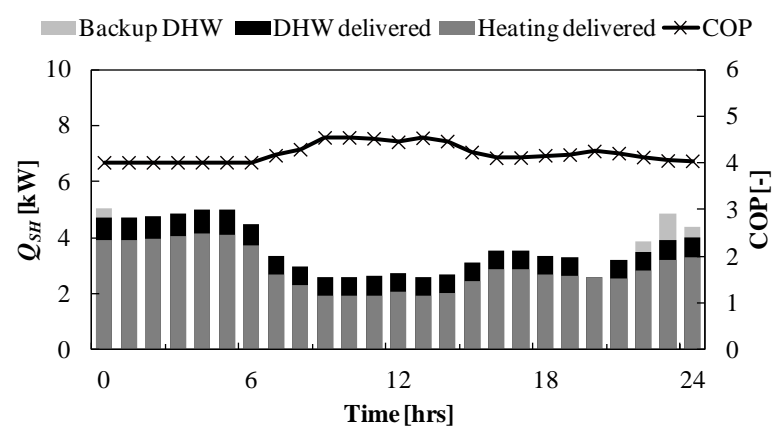

d. HP operation, Tokyo

Fig. 11. Operation of compact GSHP with a desuperheater using Scheme 1 during the coldest day of the year. 


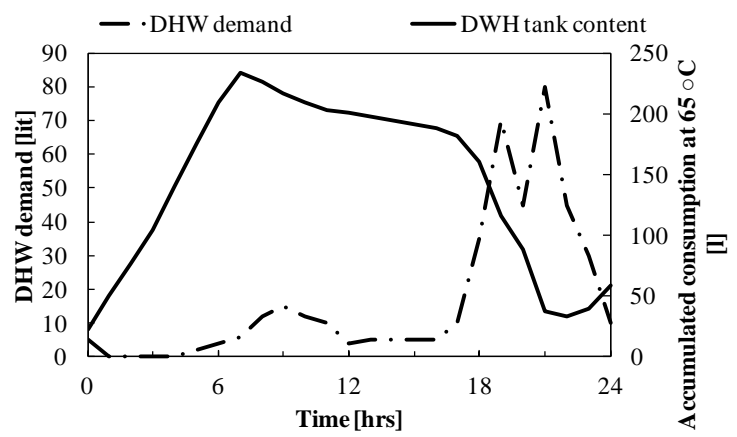

a. DHW tank, Sapporo

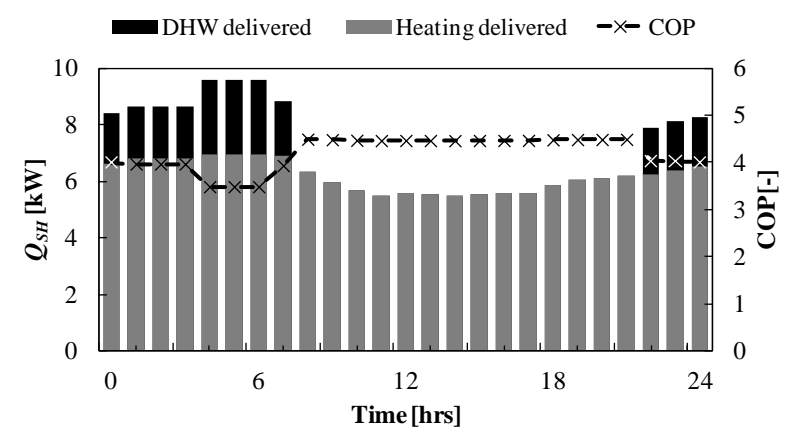

c. HP operation, Sapporo

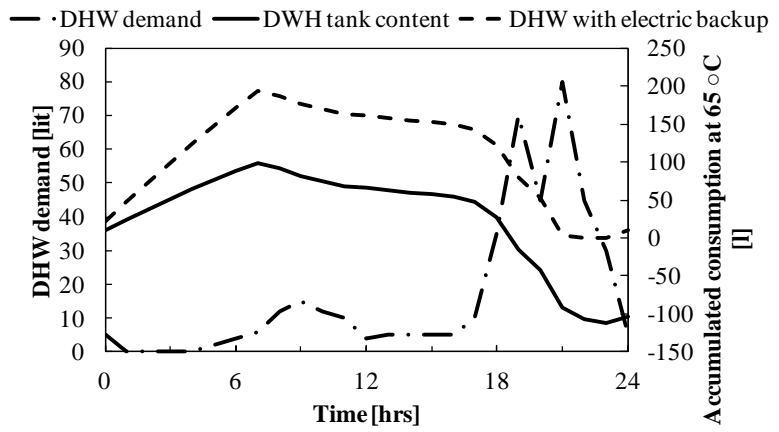

b. DHW tank, Tokyo

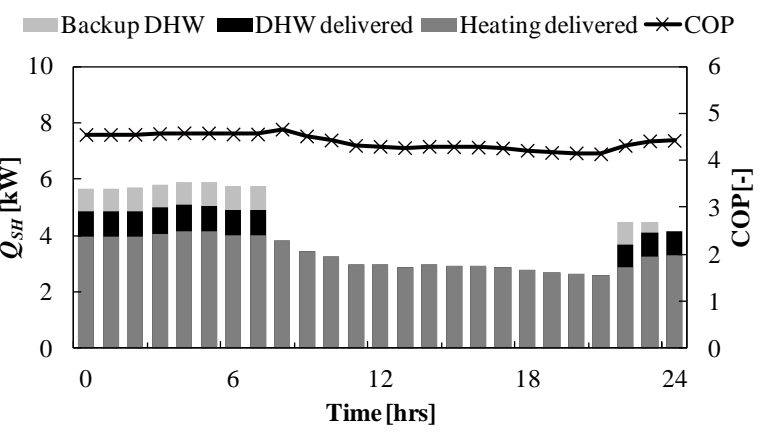

d. HP operation, Tokyo

Fig. 12. Operation of compact GSHP with a desuperheater using Scheme 2 during the coldest day of the year. 


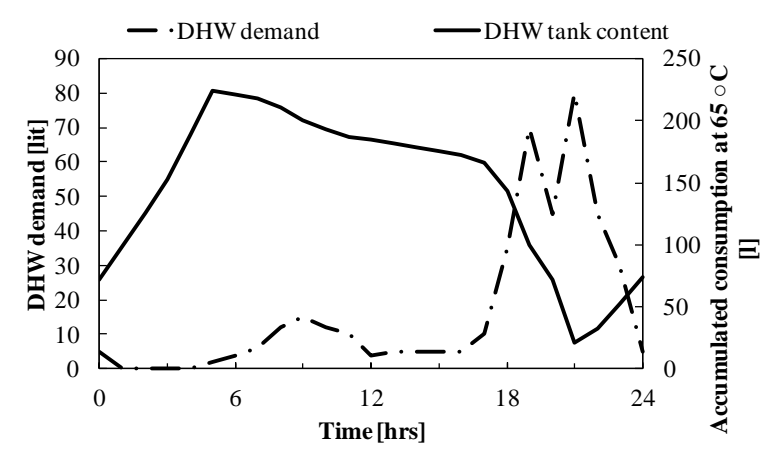

a. DHW tank, Sapporo

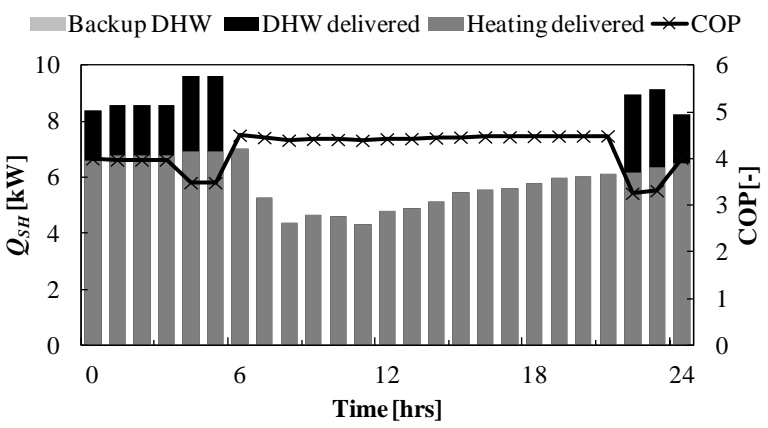

c. HP operation, Sapporo

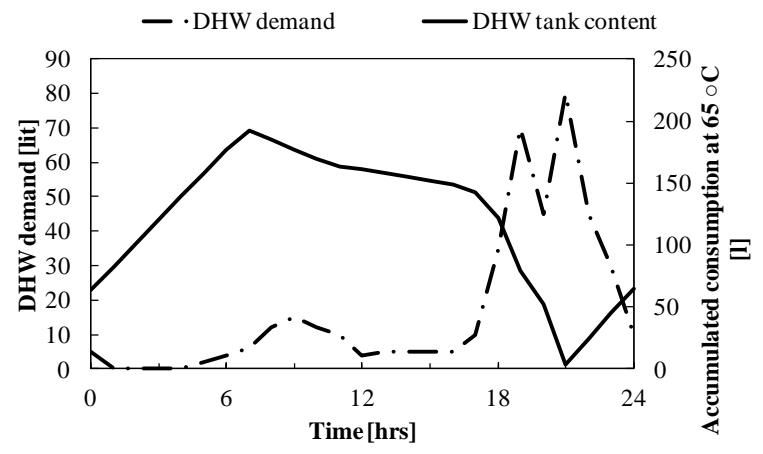

b. DHW tank, Tokyo

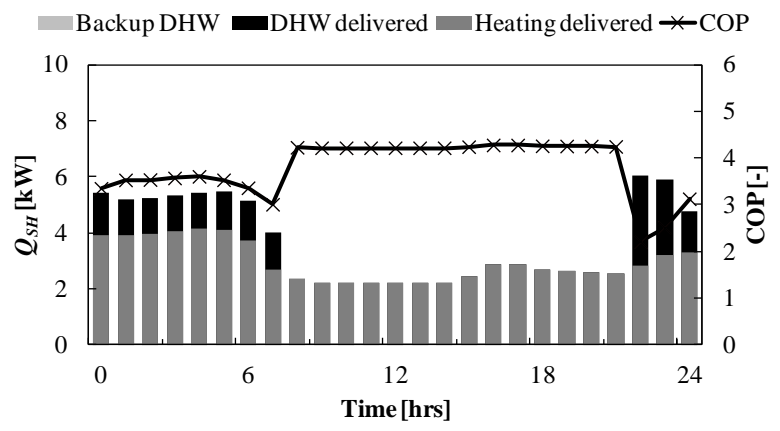

d. HP operation, Tokyo

Fig. 13. Operation of compact GSHP with a desuperheater using Scheme 3 during the coldest day of the year. 


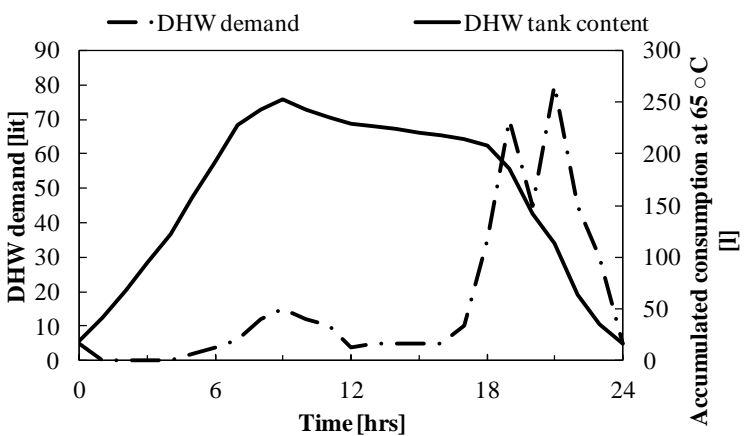

a. DHW tank, Sapporo

Backup DHW $=$ DHW delivered - Heating delivered $*$ COP

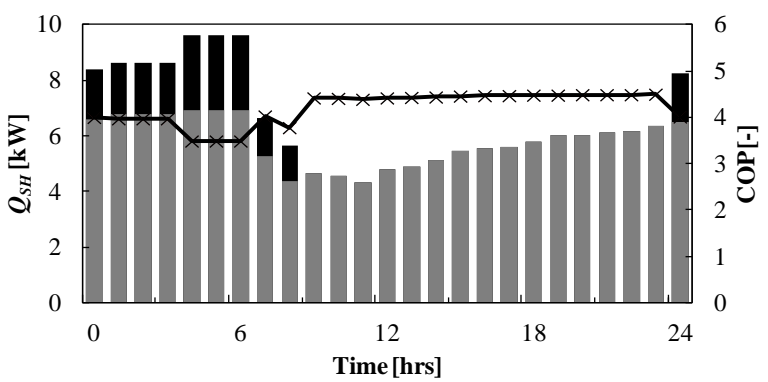

c. HP operation, Sapporo

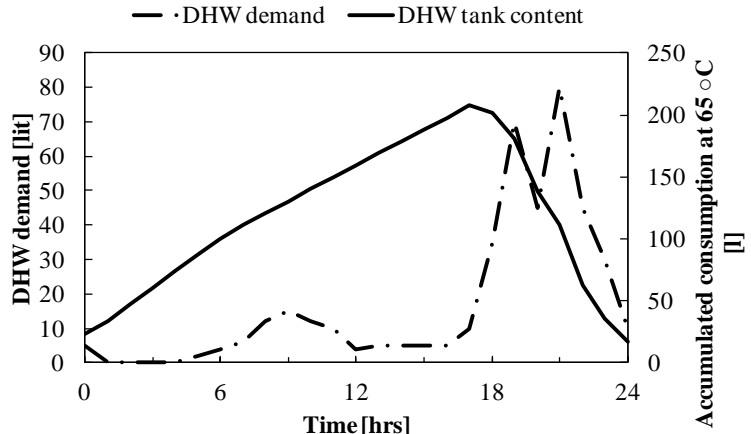

b. DHW tank, Tokyo

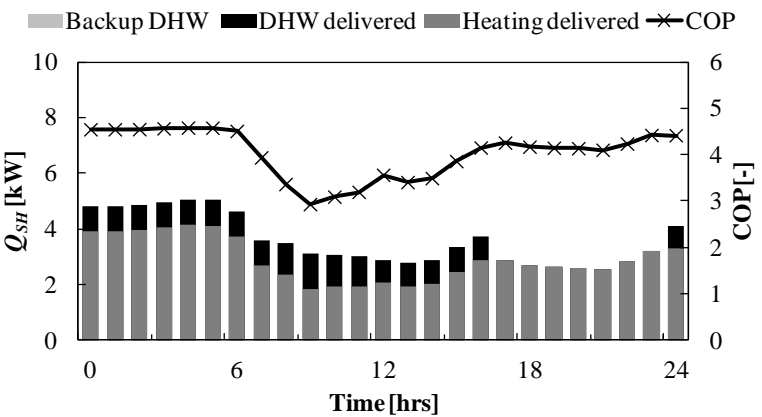

d. HP operation, Tokyo

Fig. 14. Operation of compact GSHP with a desuperheater using Scheme 4 during the coldest day of the year. 


\section{List of Tables}

Table 1. Operation modes of the compact GSHP with a desuperheater.

\begin{tabular}{clllll}
\hline Operation & Operation mode & Primary side heat direction & \multicolumn{3}{c}{ Secondary side } \\
& & & DHW & SH & SC \\
\hline \multirow{3}{*}{ Heating } & SH (mode 1) & extraction & off & on & off \\
& DHW (mode 2) & extraction & on & off & off \\
& SH\&DHW (mode 3) & extraction & on & on & off \\
& & & & & \\
\multirow{5}{*}{ Cooling } & SC (mode 4) & injection & off & off & on \\
& SC\&DHW (mode 5) & off & on & off & on \\
& SC\&DHW (mode 6) & injection & on & off & on \\
\hline
\end{tabular}

Prepared by David Blanco, Katsunori Nagano and Masahiro Morimoto 
Table 2. Simulation mapping climate conditions.

\begin{tabular}{rlllll}
\hline Operation mode & $\boldsymbol{T}_{\boldsymbol{e} 1}\left[{ }^{\circ} \mathbf{C}\right]$ & $\boldsymbol{T}_{\boldsymbol{d} 2^{\prime}}\left[{ }^{\circ} \mathbf{C}\right]$ & $\boldsymbol{T}_{\boldsymbol{d 2}}{ }^{\prime}\left[{ }^{\circ} \mathbf{C}\right]$ & $\boldsymbol{T}_{\boldsymbol{c} 2}{ }^{\prime}\left[{ }^{\circ} \mathbf{C}\right]$ & freq $[\mathrm{Hz}]$ \\
\hline SH only (mode 1) & $-5,0,5$ & - & - & 35 & $90,75,60,45,30$ \\
DHW only (mode 2) & $-5,0,5$ & $5,17,30$ & 65 & - & $90,75,60,45,30$ \\
SH\&DHW (mode 3) & $-5,0,5$ & $5,17,30$ & 65 & 35 & $90,75,60,45,30$ \\
\hline
\end{tabular}

Prepared by David Blanco, Katsunori Nagano and Masahiro Morimoto 
Table 3. Evaluated low energy house (Air volume $=320 \mathrm{~m}^{3}$, Q factor $=0.96 \mathrm{Wm}^{2} \mathrm{~K}^{-1}$ ).

\begin{tabular}{lcccc}
\hline Surface & $\begin{array}{c}\text { insulation }[\mathbf{m m}] \\
\text { U value }\left[\mathbf{W m}^{-2} \mathbf{K}^{-1}\right]\end{array}$ & \multicolumn{2}{c}{ Area $\left[\mathbf{m}^{2}\right]$} \\
\hline Ceiling & 240 & & 200 & \\
& 2.9 & N/S & E/W & Total \\
Walls & 100 & 50 & 16 & 132 \\
& 2.1 & & 200 & \\
Floor & 50 & & & \\
& 1.6 & N/S & E/W & Total \\
Windows & - & 6 & 6 & 24 \\
& 4.1 & & & \\
\hline
\end{tabular}

Prepared by David Blanco, Katsunori Nagano and Masahiro Morimoto 
Table 4. Comparison of operation schemes for the coldest day of the year.

\begin{tabular}{|c|c|c|c|c|c|c|c|c|}
\hline January 23 & $\begin{array}{l}\text { Scheme } 1 \\
\text { Sapporo }\end{array}$ & Tokyo & $\begin{array}{l}\text { Scheme } 2 \\
\text { Sapporo }\end{array}$ & Tokyo & $\begin{array}{l}\text { Scheme } 3 \\
\text { Sapporo }\end{array}$ & Tokyo & $\begin{array}{l}\text { Scheme } 4 \\
\text { Sapporo }\end{array}$ & Tokyo \\
\hline Cost [EUR] & 6.6 & 4.0 & 7.0 & 4.6 & 6.6 & 4.0 & 7.9 & 4.7 \\
\hline$W_{e l} /$ backup* $[\mathrm{kWh}]$ & 39.86 & $21.2 / 26.7$ & 43.3 & $21.4 / 32.8$ & 40.9 & 26.5 & 40.3 & 22.4 \\
\hline$Q_{S H}[\mathrm{kWh}]$ & 145.3 & 72.4 & 145.2 & 83.2 & 145.2 & 73.9 & 145.2 & 72.4 \\
\hline$Q_{D H W} /$ backup* $[\mathrm{kWh}]$ & 19.3 & $17.1 / 19.1$ & 22.35 & $9.8 / 17.6$ & 19.9 & 18.2 & 19.7 & 17.0 \\
\hline COP / backup* & 4.1 & $4.2 / 3.85$ & 4.1 & $4.3 / 3.2$ & 4.0 & 3.5 & 4.0 & 4.0 \\
\hline$G_{D H W}\left(65^{\circ} \mathrm{C}\right)[\mathrm{L}]$ & 275.7 & $255.4 / 281$ & 318.6 & $144.5 / 257.2$ & 282.4 & 268.6 & 277.8 & 251.0 \\
\hline
\end{tabular}

* Including electric backup heater when not all of $Q_{D H W}$ can be supplied by the system. 
Table 5. Comparison of operation schemes for the heating season.

\begin{tabular}{lllllll}
\hline \multirow{2}{*}{ Oct. 1 - May 1 } & $\begin{array}{l}\text { Scheme 1 } \\
\text { Sapporo }\end{array}$ & Tokyo & $\begin{array}{l}\text { Scheme 2 } \\
\text { Sapporo }\end{array}$ & Tokyo & \multicolumn{3}{c}{$\begin{array}{l}\text { Scheme 3 } \\
\text { Sapporo }\end{array}$} & $\begin{array}{l}\text { Scheme 4 } \\
\text { Tokyo }\end{array}$ Sapporo \\
& Tokyo
\end{tabular}

* Including electric backup heater when not all of $Q_{D H W}$ can be supplied by the system. 